\title{
"Negro é negro": a contribuição da obra de Virginia Leone Bicudo aos estudos de relações raciais
}

\author{
"Black is black": \\ the contribuition of Virginia Leone Bicudo's work \\ to the racial relations studies
}

Carla Regina Mota Alonso Diguez

\begin{abstract}
Atitudes raciais de pretos e mulatos em São Paulo Virgínia Leone Bicudo. Introdução e edição de Marcos Chor Maio. São Paulo: Editora Sociologia e Política, 2010.
\end{abstract}

A questão racial é tema de pesquisa das Ciências Sociais brasileiras desde sua institucionalização. Na década de 1940, um grupo de pesquisadores, ori-

Carla Regina Mota Alonso Diéguez é doutoranda em Ciências Sociais pela Universidade Estadual de Campinas e professora e pesquisadora da Fundação Escola de Sociologia e Política de São Paulo, São Paulo, Brasil (carlaregina@fespsp.org.br).

Resenha recebida em 29 de dezembro de 2010 e aprovada para publicação em 24 de fevereiro de 2011.

Est. Hist., Rio de Faneiro, vol. 24, no 47, p. 219-222, janeiro-junho de 2011. 
entados pelo Prof. Dr. Donald Pierson, empreendeu pesquisas sobre o tema e desenvolveu teses de mestrado e doutorado na recém-criada Divisão de Estudos Pós-Graduados da Escola Livre de Sociologia e Política. Entre eles estava Virgínia Leone Bicudo.

Mas, quem foi e o que fez Virgínia Leone Bicudo? Esta resposta está no livro Atitudes raciais de pretos e mulatos em São Paulo. Publicado pela Editora Sociologia e Política em 2010, ano em que Virgínia completaria 100 anos, e organizado por Marcos Chor Maio, o livro apresenta a figura ímpar de Virgínia Leone Bicudo e sua tese de mestrado defendida em 1945 na Escola Livre de Sociologia e Política (ELSP).

O prefácio, escrito por Élide Rugai Bastos, localiza a tese de Virgínia no contexto teórico e metodológico da época, permitindo-nos conhecer mais sobre a influência norte-americana nos estudos da nascente Ciência Social brasileira, especialmente o interacionismo simbólico, que já apontava na obra de Virgínia e apareceu, de forma mais contundente, nos trabalhos de Oracy Nogueira (1998, 2009), companheiro de Virginia na primeira turma de mestrado da ELSP. Como é sabido, a ELSP, em seus anos de formação, contou com a presença de professores norte-americanos, com destaque para Horace Davis, Samuel Lowrie e Donald Pierson, este último o responsável pela criação da Divisão de Estudos Pós-Graduados da ELSP e pelo desenvolvimento das pesquisas conhecidas por estudos de comunidade.

Ao usar Ciência Social, evidenciamos a intersecção entre a Antropologia, a Sociologia e a Psicologia Social, presente nas pesquisas realizadas na ELSP, explícita na tese de Virgínia e ressaltada por Maio na introdução do livro. Esta era a forma que Pierson concebia a ciência desenvolvida e praticada na ELSP, que extrapolava as divisões disciplinares e buscava a comunhão entre teoria $\mathrm{e}$ empiria

É esta, também, a impressão que o leitor possui ao mergulhar na obra de Virginia. A autora mostra que não é preciso desfiar teorias para realizar um trabalho expressivo, reflexivo e crítico, mas sim saber usá-las. Baseada nos trabalhos de Donald Pierson, Negroes in Brazil, e de Everett Stonequist, The Marginal Man, ela busca construir hipóteses sobre as atitudes sociais de pretos ${ }^{1}$ e mulatos quanto às questões raciais. Entretanto, mais do que hipóteses, consideramos que Virgínia chega a conclusões sobre como pretos e mulatos veem as relações raciais.

Virgínia realizou sua pesquisa entre os anos de 1941 e 1944, ao longo dos quais entrevistou 31 pessoas, divididas segundo os fenótipos (termo utilizado pela autora) de pretos e mulatos e a classe social, inferiores e intermediárias. Ela buscava, dessa forma, estabelecer uma relação entre seu trabalho e o de seu orientador, Donald Pierson, o qual anunciou a existência de um preconceito de classe 
que se sobrepunha ao preconceito de cor (Pierson, 1945). Virgínia, porém, acabou distanciando-se da análise de Pierson, dado que suas hipóteses caminharam para a afirmação da existência de um preconceito de cor, autônomo do preconceito de classe. Nesse caminho também seguiu Oracy Nogueira, que viria a cunhar, posteriormente, um termo para este tipo de preconceito, o de preconceito de marca (Nogueira, 1998).

Virgínia também entrevistou membros da Associação de Negros Brasileiros, nome fictício dado por ela para a Frente Negra Brasileira (FNB), e utilizou passagens do jornal mensal da FNB, Voz da Raça, chamado na tese de "Os Descendentes de Palmares".

Com base nesses dados, ela expõe os casos, as opiniões e atitudes dos entrevistados. Ela os apresenta conforme a divisão metodológica - pretos de classe inferior, pretos de classe intermediária, mulatos de classe inferior e mulatos de classe intermediária. Após a exposição de cada parte, são feitas reflexões sobre as atitudes apresentadas, depreendendo algumas hipóteses, as quais são reunidas na conclusão do trabalho.

Alguns depoentes têm suas entrevistas transcritas quase integralmente. O que poderia ser maçante torna o trabalho riquíssimo, demonstrando a importância dada por Virgínia ao discurso do nativo, no sentido de compreender os aspectos objetivos e subjetivos que o levam a determinadas atitudes raciais. Também transforma a obra em excelente fonte documental, possibilitando a outros pesquisadores, nos dias atuais, fazerem uso desse material e compreenderem, a partir de dados primários, como as relações raciais desenvolviam-se na década de 1940.

Os dados sobre a FNB também são de extrema importância, pois mostram como essa associação procurou agremiar pretos e mulatos no sentido de transpor as barreiras da cor e construir uma sociedade mais justa e igualitária no que concerne às relações raciais. Tanto as entrevistas com membros da FNB quanto as passagens extraídas do mensário e expostas no trabalho apresentam essa preocupação.

Ao final da tese, Virgínia elenca sete hipóteses. No que concerne à relação entre raça e classe, afirma que a ascensão do preto ou do mulato é feita pela ocupação e a educação, mas que isso não diminui a distância social em termos de cor. Os mulatos integram-se mais facilmente ao grupo dominante, talvez, como aponta a autora, pela sua condição de híbrido, o que a leva à hipótese final. Para Virgínia, trata-se "de discriminação baseada na cor, visto perder significação desde que o indivíduo apresente características do grupo dominante e na medida em que sua pele vai 'branqueando', não sendo, portanto, levada em conta sua origem” (Bicudo, 2010: 163). 
Com orelha assinada por Maria Laura Viveiros de Castro Cavalcanti e depoimentos na quarta capa de Antonio Sergio Alfredo Guimarães, Peter Fry, Mariza Correa, Joel Rufino dos Santos, Maria Angela Moretzsohn e Maria Helena Teperman, a tese de Virginia Leone Bicudo - visitadora sanitária, socióloga e psicanalista, publicada pela primeira vez na íntegra $-^{2}$ é uma excelente fonte para compreendermos não só o desenvolvimento das Ciências Sociais no Brasil, mas principalmente para entendermos as relações raciais na primeira metade do século XX.

\section{Notas}

1. Usarei aqui os termos utilizados pela autora.

Referências bibliográficas

BICUDO, Virgínia Leone. Atitudes raciais de pretos e mulatos em São Paulo. Sociologia, São Paulo, Escola Livre de Sociologia e Política de São Paulo, v. 9, n. 3, p. 196-219, 1947.

.Atitudes raciais de pretos e mulatos em São Paulo. Introdução e edição de Marcos Chor Maior. São Paulo: Editora Sociologia e Política, 2010.

NOGUEIRA, Oracy. Preconceito de marca. As relações raciais em Itapetininga. Apresentação e edição de Maria Laura Viveiros
2. Parte da tese foi publicada em artigo pela revista Sociologia (Bicudo, 1947).

de Castro Cavalcanti. São Paulo, Edusp, 1998.

Vozes de Campos de Fordão: experiências sociais e psíquicas de tuberculoso pulmonar no estado de São Paulo. $2^{\mathrm{a}}$ ed. organizada por Maria Laura Viveiros de Castro Cavalcanti. Rio de Janeiro: Editora Fiocruz, 2009.

PIERSON, Donald. Brancos e Pretos na Bahia: estudo de contato racial. São Paulo: Companhia Editora Nacional, 1945 